\title{
Pemanfaatan Framework Web dalam Pengadministrasian Penyaluran Raskin
}

\section{Utilization of the Web Framework in Administering Poor Rice Distribution}

\author{
Okkita Rizan*1 $^{*}$, Hamidah $^{2}$, Hengki $^{3}$, Novalia $^{4}$ \\ ${ }_{1,2,3,4}$ STMIK Atma Luhur; Jln. Jend. Sudirman Pangkalpinang, telp. 0717-433506 \\ 1,2,3,4 Jurusan Sistem Informasi, Pangkalpinang \\ e-mail: *110rizan@atmaluhur.ac.id, ${ }^{2}$ hamidah@ atmaluhur.ac.id, ${ }^{3}$ hengki@atmaluhur.ac.id , \\ ${ }^{4} 1422500089 @$ mahasiswa.atmaluhur.ac.id
}

\begin{abstract}
Abstrak
Salah satu bentuk penerapan sila kelima Pancasila yang dilakukan oleh pemerintah dalam mewujudkan keadilan sosial bagi seluruh rakyat Indonesia adalah dengan memberikan bantuan bagi warga kurang mampu berupa beras, yang sangat dikenal dengan istilah raskin. Biasanya pembagian beras ini dilakukan oleh kantor desa ataupun kantor kelurahan. Adapun penelitian diambil di Desa Bintet Belinyu Kabupaten Bangka Propinsi Kepulauan Bangka Belitung. Penelitian ini bertujuan untuk membantu merancang sistem informasi penyaluran raskin berbasis web yang dapat membantu pihak kelurahan dalam mengelola penyaluran raskin agar tepat sasaran. Adapun permasalahannya adalah proses pendataan calon penerima raskin terlalu lama, adanya nama penerima ganda, kesulitan dalam pencetakan kartu raskin serta pengiriman laporan penyaluran raskin kepada tim koordinasi raskin kecamatan sering mengalami keterlambatan. Metode penelitian yang digunakan metode FAST (Framework for the Application of System Thinking). Hasil penelitian ini menghasilkan sistem informasi penyaluran raskin berbasis web menggunakan framework berupa bootstrap yang sangat membantu mempermudah mendesain tampilan dan pengkodean programnya. Dengan sistem informasi ini data penyaluran raskin tepat sasaran, tidak ada penerima ganda dan penyediaan laporan menjadi lebih cepat, tepat dan akurat.
\end{abstract}

Kata kunci-Raskin, Sistem Informasi, FAST.

\begin{abstract}
One of application of the fifth of Pancasila carried out by the government in realizing social justice for all Indonesian people is by providing assistance to poor people in the form of rice, known as raskin. Usually the distribution of rice is done by the village office or kelurahan. The research was taken in Belinyu Bintet Village, Bangka Regency, Bangka Belitung Islands Province. This study aims to help design a web-based raskin distribution information system that can help the kelurahan in managing the distribution of Raskin to be on target. The problem is that the process of data collection of prospective Raskin recipients is too long, the existence of multiple recipient names, difficulties in printing Raskin cards and the sending of Raskin distribution reports to the Raskin coordination team of the kecamatan often experience delays. The research method used is the FAST method (Framework for Systems Thinking Applications). The results of this study resulted in a web-based raskin distribution information system using a framework in the form of bootstrap which greatly helped simplify program design and coding. With this information system, Raskin's data distribution is right on target, there are not many recipients and the provision of reports is faster, more precise and accurate.
\end{abstract}

Keywords—Raskin, Information System, FAST 


\section{PENDAHULUAN}

Jumlah penduduk miskin di Indonesia per September mencapai 26,52 juta orang atau berkurang 1,19 juta orang dibandingkan Maret 2017. Dengan demikian, presentase penduduk miskin di Indonesia mencapai 10,12 persen atau yang terendah sejak 16 tahun terakhir. Berdasarkan data BPS, persentase penduduk miskin Septembet 2017 menurun 0,52 persen dibandingkan Maret 2017 yang sebesar 10,64 persen. Sementara jumlah penduduk miskin turun menjadi 26,58 juta dari sebelumnya Maret 2017 sebesar 27,77 juta. Disparitas kemiskinan perkotaan dan pedesaan masih tinggi. Berdasarkan data BPS, persentase kemiskinan di perkotaan 7,26 persen. Sementara persentase kemiskinan di desa sebesar 13,47 persen. Berdasarkan data tersebut dapat disimpulkan bahwa tingkat kemiskinan masih banyak di pedesaan $^{[1]}$.

Kepala Badan Pusat Statistik Suhariyanto mengatakan, definisi penduduk miskin dalam survey ini adalah penduduk yang memiliki rata-rata pengeluaran per kapita di bawah garis kemiskinan. Metode ini digunakan BPS sejak tahun 1998, agar hasil perhitungan konsisten dan terbanding dari waktu kewaktu. ${ }^{[2]}$

Salah satu lembaga pemerintahan yang menangani pendataan masyarakat miskin/kurang mampu agar mendapat bantuan seperti raskin di pulau bangka yaitu Kantor Desa Bintet di kota Belinyu. Adapun masalahnya proses pendataan calon penerima raskin terlalu lama, adanya nama penerima ganda, kesulitan dalam pencetakan kartu raskin serta pengiriman laporan penyaluran raskin kepada tim koordinasi raskin kecamatan sering mengalami keterlambatan. Maka dari itu untuk meningkatkan kualitas pelayanan terhadap masyarakat miskin/kurang mampu di Desa Bintet, maka perlu dibuat sistem informasi yang dapat mengatasi permasalahan yang ada.

Untuk menghadapi masalah tersebut, maka diperlukan suatu sistem yang dapat mengelola berbagai informasi yang terkait dengan pengolahan data masyarakat miskin/kurang mampu. Solusi tersebut dilihat sebagai kesempatan untuk memberikan kontribusi bagi kantor desa untuk mempermudah para pegawai atau staff dalam pengolahan data masyarakat miskin/kurang mampu dengan memanfaatkan teknologi informasi melalui sistem informasi yang telah dibuat.

Seiring dengan perkembangan, bahasa pemrograman yang biasa digunakan untuk membuat sebuah aplikasi, telah diperbaharui dengan sedemikian rupa untuk mempermudah programmer menciptakan sebuah aplikasi sistem informasi. Salah satunya adalah menggunakan framework berupa bootstrap. Keuntungan dari framework ini adalah merancang interface aplikasi lebih gampang dan susunan sintak program dapat dipahami dengan mudah.

Penelitian yang penulis jadikan referensi diantaranya penelitian Titis Aji Wicaksono, Siti Aminah (2018). Penelitian ini berjudul "Sistem Informasi Pengelolaan Raskin pada Pelaksana Distribusi Raskin Desa Jatingarang". Masalah yang ada di sistem sekarang ini adalah lamanya proses pendataan calon penerima raskin, adanya nama ganda penerima, kesulitan dalam pencetakan kartu raskin, serta keterlambatan dalam pengiriman laporan penjualan beras kepada Tim Koordinasi Raskin Kecamatan. Hasil yang didapatkan dalam penelitian ini adalah sebuah Sistem Informasi Pengelolaan Raskin berbasis web yang dapat membantu Pelaksana Distribusi Raskin Desa Jatingarang dalam menyelesaikan administrasi raskin secara cepat dan akurat, serta warga dapat mengetahui informasi tentang program raskin di desa jatingarang dengan mudah kapanpun dan dimanapun ${ }^{[3]}$.

Penelitian berikutnya berjudul "Rancang Bangun Sistem Informasi Distribusi Bantuan Sosial Beras Miskin (Studi Kasus Kecamatan Binamu Kabupaten Jeneponto". Adapun kesimpulan penelitian ini adalah Setelah melalui pengujian sistem menggunakan metode Blackbox pada software sistem informasi distribusi raskin yang menunjukkan kelayakan implementasi sistem. Kemudian didukung hasil kuisioner yang disebar pada 15 responden 
dengan hasil $54,17 \%$ menyatakan merekomendasikan penerapan sistem informasi distribusi raskin pada proses distribusi raskin berjalan. Maka kesimpulan yang dapat diambil dari penelitian ini yakni pemanfaatan sistem informasi pada proses distribusi raskin di kecamatan Binamu kabupaten Jeneponto mendorong terciptanya administrasi data yang baik dan transparansi pada proses distribusi berjalan, hingga turut mendorong tercapainya sistem regulasi distribusi raskin yang lebih baik di daerah tersebut. ${ }^{[4] .}$

Penelitian berikutnya berjudul "Pembangunan Sistem Informasi Pendataan Rakyat Miskin Untuk Program Beras Miskin (Raskin) Pada Desa Mantren Kecamatan Kebonagung Kabupaten Pacitan". Adapun kesimpulan penelitian ini adalah Sistem Pendataan Rakyat Miskin Untuk Program Raskin pada Desa Mantren masih dilakukan secara konvensional sehingga diperlukan sebuah Sistem Informasi Pendataan Rakyat Miskin Untuk Program Beras Miskin (Raskin) untuk mempermudah proses pendataan rakyat yang mendapatkan Raskin dan membantu kinerja petugas pendataan agar waktu yang dibutuhkan lebih efisien ${ }^{[5]}$.

\section{METODE PENELITIAN}

Dalam penyusunan penelitian, hal pertama yang dilakukan penulis yaitu mengambil data yang dimulai dengan penyusunan proposal, pengajuan proposal, pengambilan data, analisis data, perancangan sistem sampai pembuatan sistem. Dalam pengumpulan data dilakukan dengan cara wawancara dengan tujuan untuk memperoleh informasi yang berkaitan dengan penyaluran raskin. Wawancara dilakukan dengan pihak kelurahan yang mengurus masalah penyaluran raskin. Studi literatur dengan cara mencari referensi dari buku-buku, artikel dan jurnal sedangkan dokumentasi berjalan dengan cara menganalisa dokumen yang didapat dari kelurahan. Tahapan selanjutnya, perancangan sistem dimulai dengan penggambaran proses bisnis menggunakan activity diagram, rancangan basis data dengan menggunakan diagram keterhubungan entitas dan perancangan antar muka atau interface untuk sistem informasi yang akan digunakan oleh staff kelurahan dalam penyaluran raskin dengan menggunakan use case diagram dan implementasi antar muka dengan menggunakan aplikasi yang sudah dibuat.

Selesai tahapan perancangan sistem, yang berikutnya adalah pengujian sistem, pengujian yang digunakan dalam penelitian ini adalah menggunakan black box. Pengujian ini dilakukan untuk melihat apakah sistem informasi yang dirancangan sudah sesuai atau belum dan apakah fungsionalitas dari sistem dapat berjalan sesuai dengan yang dibutuhkan.

Dalam penyusunan penelitian, penulis menggunakan tahapan dalam model FAST (Framework For the Application of System Thinking) dalam pengembangan perangkat lunaknya sesuai dengan kebutuhan penyelesaian penelitian yaitu scope definition, problem analysis, requirements analysis, decision analysis, logical desain, physical desain, logical desain dan testing. Beberapa tahapan menggunakan metode berorientasi objek terutama pada saat proses analisa dan desain sistem, juga menggunakan metode terstruktur dalam perancangan basis datanya. Dalam tahapan implementasi, penulis menyusun aplikasi menggunakan framework berbasis web dan mySQL untuk basis datanya. ${ }^{[6]}$

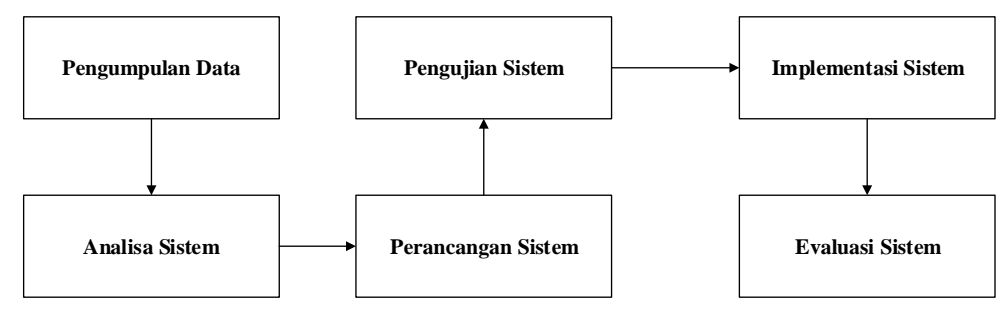

Gambar 1 Metode Penelitian 


\section{HASIL DAN PEMBAHASAN}

\subsection{Definisi Lingkup}

Berdasarkan hasil reservasi pada objek penelitian, proses penyaluran raskin melibatkan warga, pemerintah daerah, petugas pendistribusian dan negara. Proses penyaluran terbagi kedalam beberapa tahapan yang dilaksanakan secara berurutan yaitu pendataan awal calon penerima raskin, pengumpulan berkas dan dokumen bagi warga yang telah ditetapkan menjadi penerima raskin, penerimaan dan ditutup dengan pendistribusian raskin. Selain itu, proses yang tidak kalah pentingnya adalah proses mengganti penerima raskin yang sudah tidak berhak lagi mendapat bantuan. Simpulan tahapan sistem berjalan penyaluran raskin dapat dilihat pada beberapa activity diagram sebagai berikut :
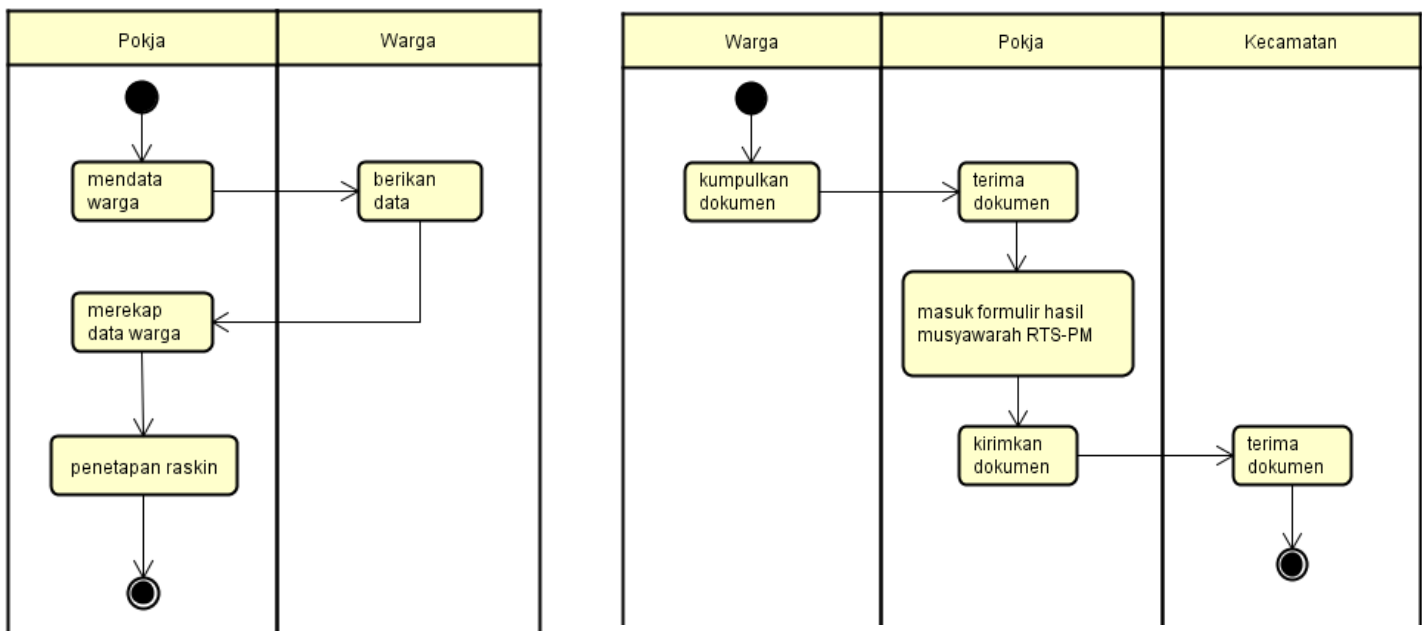

Gambar 2 Pendataan dan pengumpulan berkas

Pada Gambar 2 dijelaskan bahwa Pokja mendata warga yang akan menerima Raskin kemudian warga mengumpulkan dokumen. Setelah itu Pokja mengirimkan dokumen ke kecamatan.
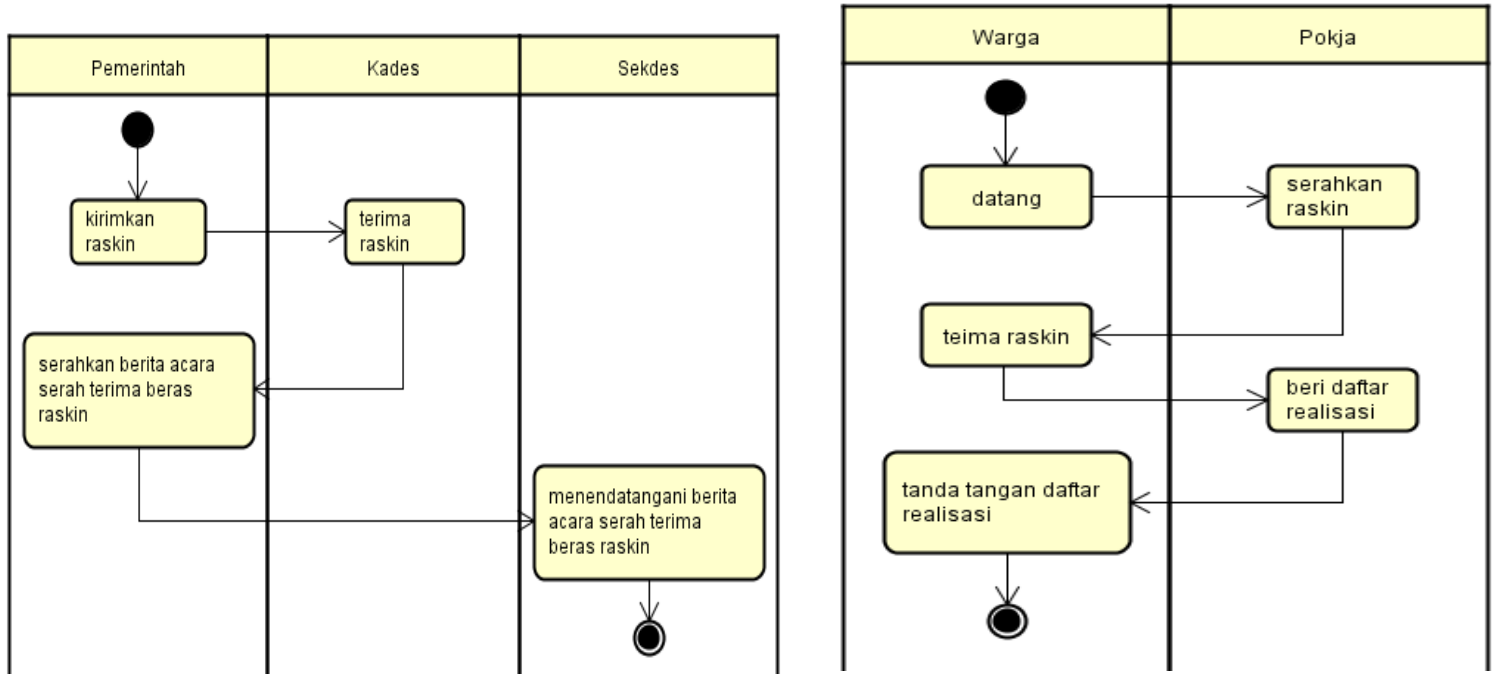

Gambar 3 Pengambilan dan pendistribusian raskin 
Pada Gambar 3 dijelaskan bahwa Pemerintah mengirimkan raskin kepada kades dan kades menandatangani berita acara serah terima. Kemudian Pokja menyerahkan raskin kepada warga.

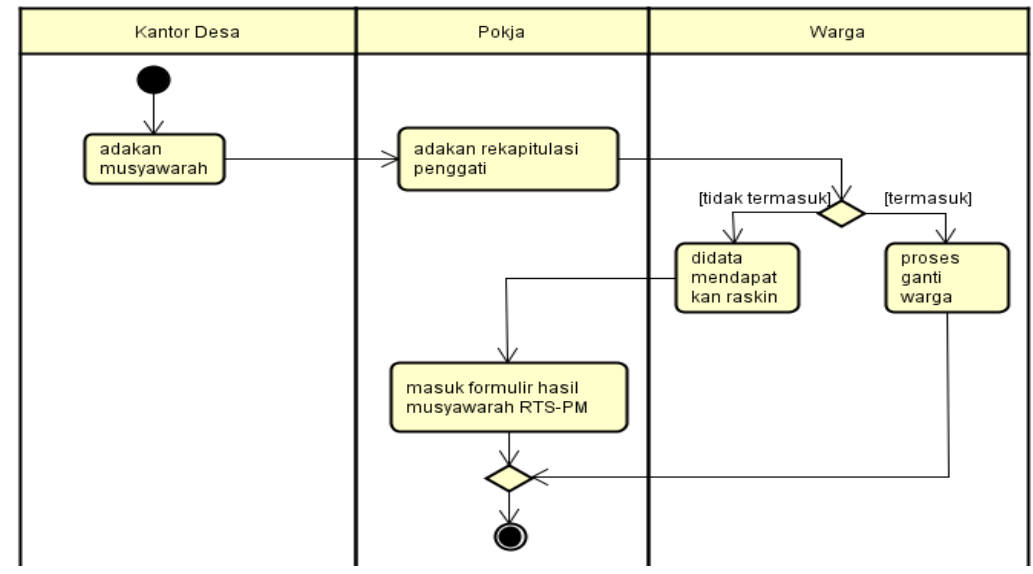

Gambar 4 Penggantian penerima raskin

Pada Gambar 4 dijelaskan bahwa kantor desa mengadakan musyawarah, Pokja mengadakan rekapitulasi pengganti. Pokja membuat formulir hasil musyawarah RTS-PM yang berisi data warga yang diganti.

\subsection{Problem Analysis}

Dari hasil analisis proses penyaluran raskin, dapat diidentifikasi beberapa masalah pada sistem berjalan tersebut diantaranya dapat dilihat pada gambar berikut.

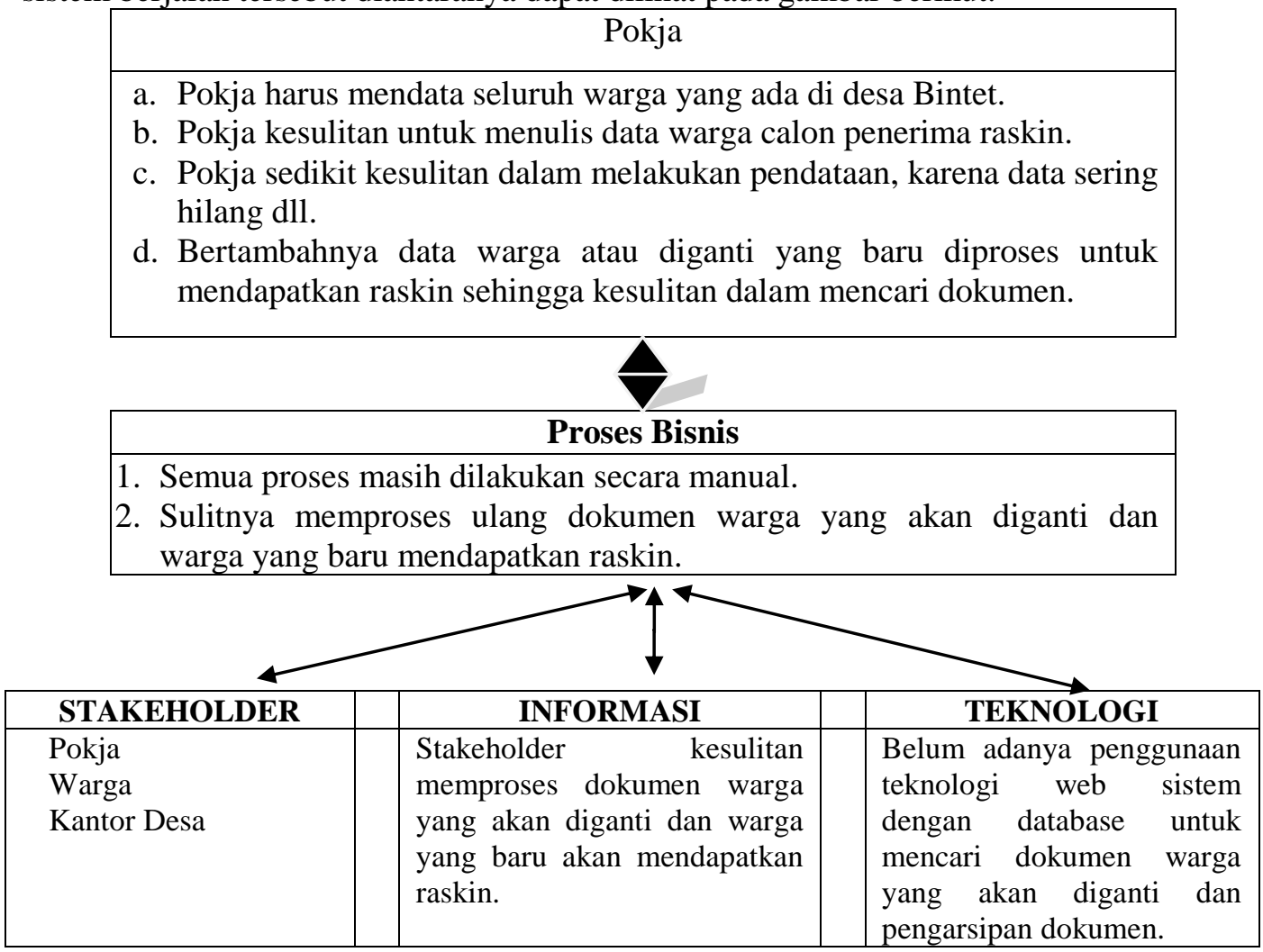

Gambar 5 Analisis masalah 


\subsection{Decision Analysis}

Berdasarkan karakteristik proses dan hasil identifikasi permasalahan pada sistem berjalan, penelitian ini mengambil keputusan untuk membuat sebuah sistem informasi berbasis web dengan database yang secara realtime dapat di update. Keputusan ini diambil berdasarkan beberapa pertimbangan diantaranya adalah kemudahan dalam mendata warga yang layak menjadi kandidat penerima raskin, perekaman data yang lebih terstruktur dan mengurangi biaya operasional serta cepat dalam menyajikan laporan yang diperlukan dalam pengadministratian penyaluran raskin. Untuk memudahkan pembuatan aplikasinya, diputuskan untuk menggunakan sebuah framework yang telah menyediakan template interface dan web service khusus.

\subsection{Requirement Analysis}

Untuk mengatasi permasalahan pada sistem yang berjalan dengan mengikuti analisis keputusan pembuatan sistem yang telah diambil, dapat ditentukan beberapa kebutuhan sistem yang diperlukan, diantaranya adalah perlu di desain interface untuk memvalidasi pengguna yang akan menggunakan sistem, interface untuk mendata dan mengolah data warga penerima raskin, interface untuk penerimaan dan penyaluran raskin ke warga, serta interface untuk pencetakan laporan yang di perlukan. Untuk penyimpanan datanya, perlu didesain sebuah database dengan tabel yang telah terkorelasi dengan baik antara satu dengan yang lain.

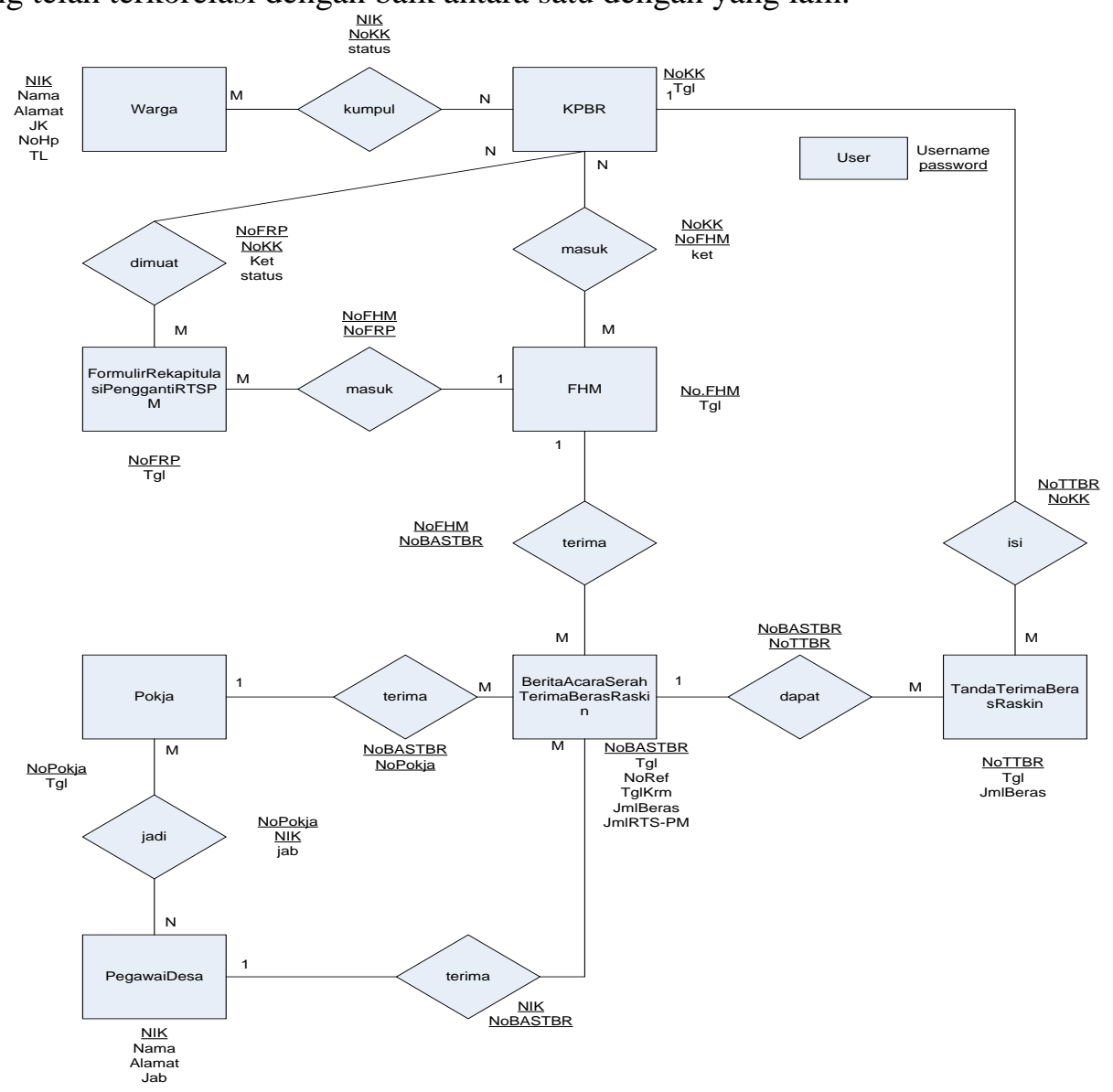

Gambar 6 Diagram ER Sistem Penyaluran Raskin

\subsection{Perancangan Antarmuka}

Pada tahapan ini, penulis mendesain interface dibantu dengan use case diagram yang telah disajikan pada gambar berikut. Desain interface didasarkan pada analisis kebutuhan dengan membuat interface login sebagai form untuk memvalidasi pengguna, membuat interface 
untuk mendata dan mengolah data, serta interface untuk proses penyaluran dan pelaporan hasil pendistribusian raskin.

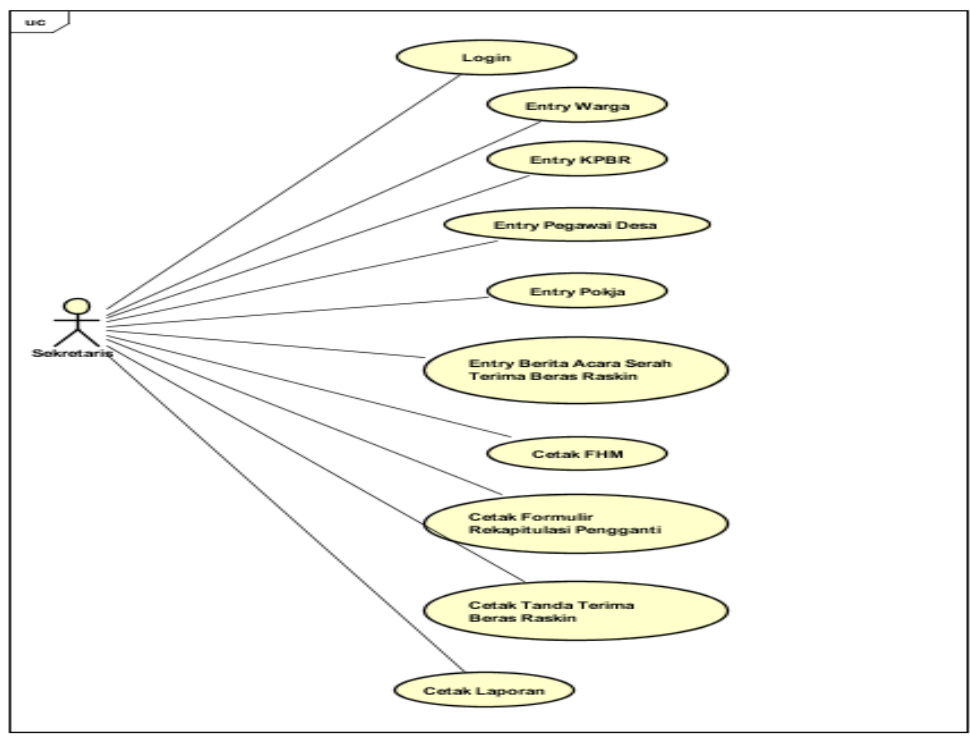

Gambar 7 Use Case Diagram Desain Interface

Pada Gambar 6 dijelaskan bahwa sekretaris melakukan login terlebih dahulu kemudian menginput data warga, KPBR, Pegawai Desa, Pokja, Berita Acara Serah Terima, cetak FHM, formulir rekapitulasi pengganti, Tanda Terima Beras Raskin dan Laporan Penerima Raskin.

3.6 Hasil Implementasi Antarmuka

Berikut beberapa rancangan fisik yang akan dijadikan acuan dalam mendesain sistemnya. Beberapa rancangan fisik ini meliputi proses untuk pendataan, transaksi maupun proses pencetakan laporan. Rancangan fisik dapat dilihat dibawah ini :

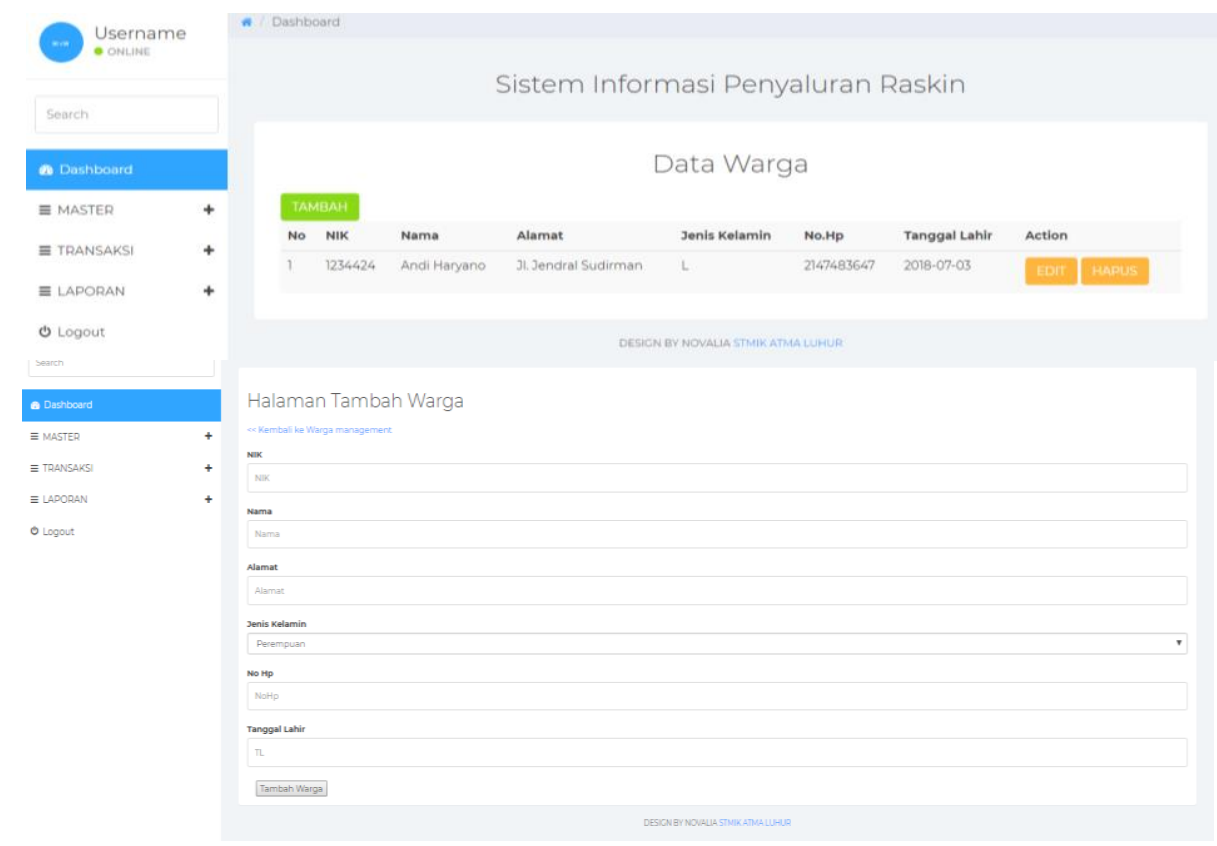

Gambar 8 Desain Interface Entry Warga 
Pada Gambar 7 dijelaskan bahwa user menginput data warga yaitu NIK, Nama, Alamat, Jenis Kelamin, No. HP dan Tanggal Lahir kemudian klik Tambah Warga sehingga tersimpan kedalam database. User dapat mengubah data warga dengan cara klik edit dan user dapat menghapus data warga dengan cara klik hapus.

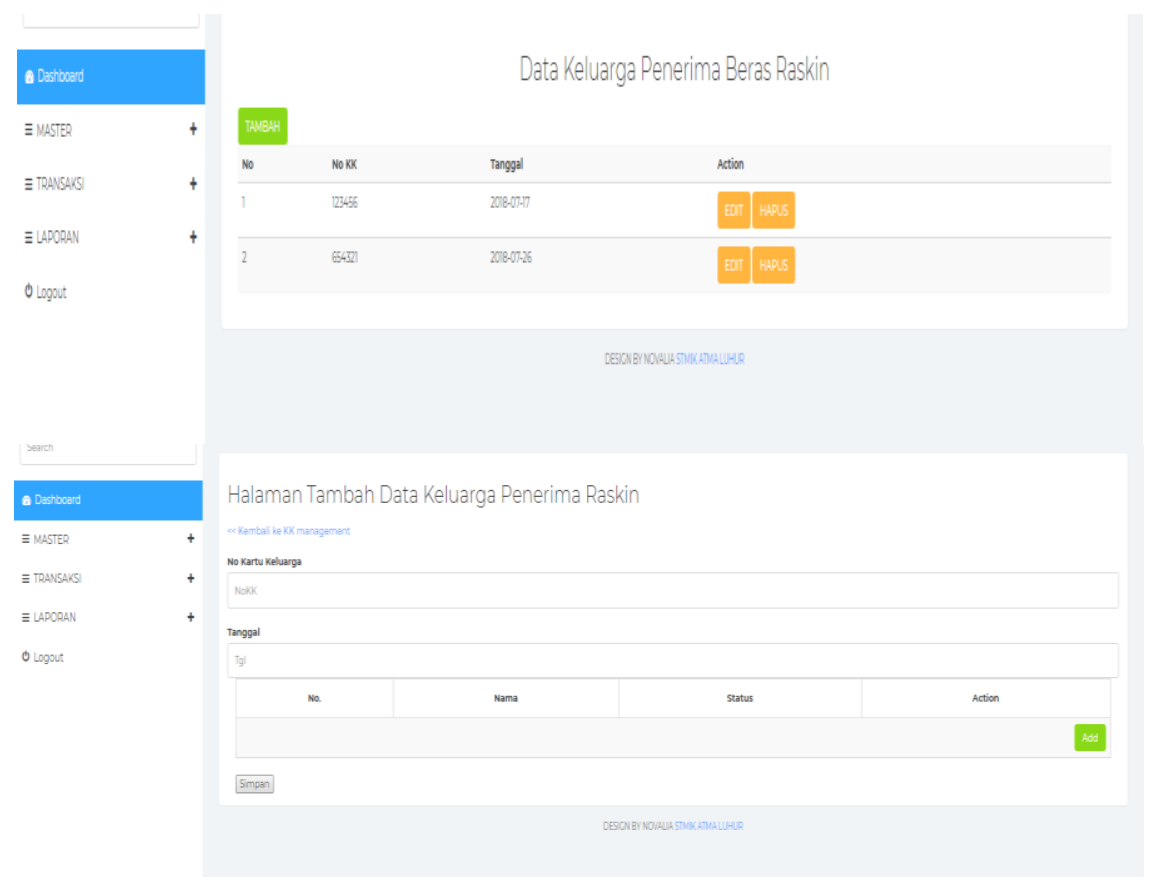

Gambar 9 Desain Interface Entry Kartu Keluarga

Pada Gambar 8 dijelaskan bahwa user menginput data kartu keluarga yaitu nomor kartu keluarga, tanggal, memilih data warga kemudian klik Simpan sehingga tersimpan kedalam database. User dapat mengubah data warga dengan cara klik edit dan user dapat menghapus data warga dengan cara klik hapus.

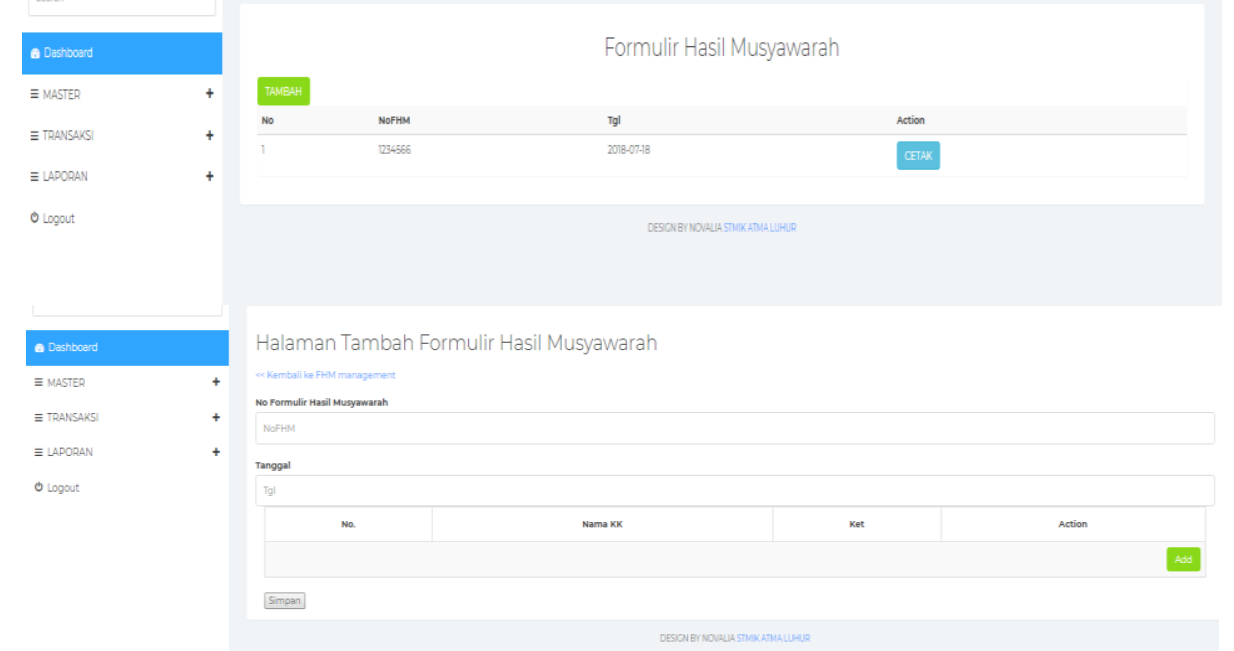

Gambar 10 Desain Interface Cetak Hasil Musyawarah

Pada Gambar 9 dijelaskan bahwa user menginput data formulir hasil musyarah yaitu nomor formulir, tanggal, memilih data warga kemudian klik Simpan sehingga tersimpan kedalam database. User dapat mengubah data warga dengan cara klik edit dan user dapat menghapus data warga dengan cara klik hapus. 
FORIIULIR HASIL MIUSYAWARAH
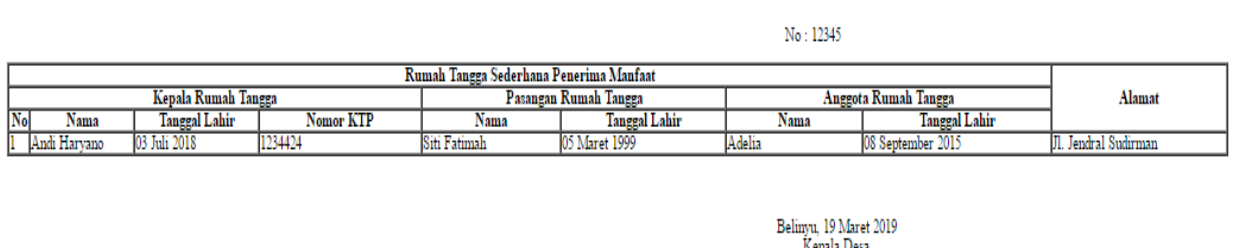

Kepala Dess

Desa Buntet

Gambar 11 Desain Interface Keluaran Hasil Musywarah

Pada Gambar 10 dijelaskan bahwa user mencetak formulir hasil musyawarah dengan cara mengklik tombol Cetak sehingga keluar hasil keluaran seperti diatas.

\subsection{Pengujian}

Setelah program selesai dibuat, maka akan dilanjutkan pengujian terhadap sistem pengadministrasian penyaluran raskin. Pengujian ini dimaksudkan untuk mengetahui seberapa jauh program tersebut berjalan dan seberapa banyak kesalahan yang ada pada program tersebut. Bila terjadi kesalahan, maka program tersebut akan segera diperbaiki dan diuji kembali. Pada tahap ini, peneliti menggunakan metode pengujian unit dengan pendekatan blackbox testing. Cara pengujian yang dilakukan dengan menjalankan aplikasi pengadministrasian penyaluran raskin yaitu melakukan input data dan melihat outputnya apakah sudah sesuai dengan proses atau hasil yang diharapkan.

Tabel 1. Pengujian Menu Utama Sistem Informasi Penyaluran Raskin

\begin{tabular}{|c|c|c|c|c|}
\hline Pengujian & $\begin{array}{l}\text { Data } \\
\text { Input }\end{array}$ & Skenario & Hasil & Keterangan \\
\hline \multirow[t]{2}{*}{ Konten } & Benar & $\begin{array}{l}\text { Konten diisi dengan lengkap dan } \\
\text { sesuai lalu tekan tombol simpan }\end{array}$ & Data Tersimpan & Sesuai \\
\hline & Salah & $\begin{array}{c}\text { Konten diisi dengan tidak lengkap } \\
\text { dan ada yang tidak sesuai }\end{array}$ & $\begin{array}{l}\text { Menampilkan message } \\
\text { kesalahan yang harus } \\
\text { diperbaiki }\end{array}$ & Sesuai \\
\hline \multirow[t]{2}{*}{ Slide } & Benar & $\begin{array}{l}\text { Slide diisi dengan lengkap dan sesuai } \\
\text { lalu tekan tombol simpan }\end{array}$ & Data Tersimpan & Sesuai \\
\hline & Salah & $\begin{array}{l}\text { Slide diisi dengan tidak lengkap dan } \\
\text { ada yang tidak sesuai }\end{array}$ & $\begin{array}{l}\text { Menampilkan message } \\
\text { kesalahan yang harus } \\
\text { diperbaiki }\end{array}$ & Sesuai \\
\hline \multirow[t]{2}{*}{$\begin{array}{c}\text { Pesan } \\
\text { Validasi } \\
\end{array}$} & Benar & $\begin{array}{l}\text { Pesan Validasi diisi dengan lengkap } \\
\text { dan sesuai lalu tekan tombol simpan }\end{array}$ & Data Tersimpan & Sesuai \\
\hline & Salah & $\begin{array}{l}\text { Pesan Validasi diisi dengan tidak } \\
\text { lengkap dan ada yang tidak sesuai } \\
\text { Menampilkan }\end{array}$ & $\begin{array}{l}\text { Menampilkan message } \\
\text { kesalahan yang harus } \\
\text { diperbaiki }\end{array}$ & Sesuai \\
\hline \multirow[t]{2}{*}{ Footer } & Benar & $\begin{array}{l}\text { Footer diisi dengan lengkap dan } \\
\text { sesuai lalu tekan tombol simpan } \\
\text { Data }\end{array}$ & Data Tersimpan & Sesuai \\
\hline & Salah & $\begin{array}{l}\text { Footer diisi dengan tidak lengkap } \\
\text { dan ada yang tidak sesuai }\end{array}$ & $\begin{array}{l}\text { Menampilkan message } \\
\text { kesalahan yang harus } \\
\text { diperbaiki }\end{array}$ & Sesuai \\
\hline
\end{tabular}


Tabel 2. Pengujian Entry Data Warga Sistem Informasi Penyaluran Raskin

\begin{tabular}{ccccc}
\hline Pengujian & $\begin{array}{c}\text { Data } \\
\text { Input }\end{array}$ & Skenario & Hasil & Keterangan \\
\hline $\begin{array}{c}\text { Penambahan } \\
\text { Data Warga }\end{array}$ & Benar & $\begin{array}{c}\text { Form diisi dengan lengkap dan } \\
\text { sesuai lalu tekan tombol simpan }\end{array}$ & Data Tersimpan & Sesuai \\
\hline $\begin{array}{c}\text { Penambahan } \\
\text { Data warga }\end{array}$ & Salah & $\begin{array}{c}\text { Form diisi dengan tidak lengkap } \\
\text { dan ada yang tidak sesuai }\end{array}$ & $\begin{array}{c}\text { Menampilkan message } \\
\text { kesalahan yang harus } \\
\text { diperbaiki }\end{array}$ & Sesuai \\
\hline
\end{tabular}

Tabel 3. Pengujian Entry Data Keluarga Penerima Raskin Sistem Informasi Penyaluran Raskin

\begin{tabular}{|c|c|c|c|c|}
\hline Pengujian & $\begin{array}{l}\text { Data } \\
\text { Input }\end{array}$ & Skenario & Hasil & Keterangan \\
\hline $\begin{array}{c}\text { Penambahan } \\
\text { Data } \\
\text { Keluarga } \\
\end{array}$ & Benar & $\begin{array}{l}\text { Form diisi dengan lengkap dan } \\
\text { sesuai lalu tekan tombol simpan }\end{array}$ & Data Tersimpan & Sesuai \\
\hline $\begin{array}{c}\text { Penambahan } \\
\text { Data } \\
\text { Keluarga }\end{array}$ & Salah & $\begin{array}{l}\text { Form diisi dengan tidak lengkap } \\
\text { dan ada yang tidak sesuai }\end{array}$ & $\begin{array}{c}\text { Menampilkan message } \\
\text { kesalahan yang harus } \\
\text { diperbaiki }\end{array}$ & Sesuai \\
\hline
\end{tabular}

Tabel 4. Pengujian Entry Formulir Hasil Musyawarah Sistem Informasi Penyaluran Raskin

\begin{tabular}{ccccc}
\hline Pengujian & $\begin{array}{c}\text { Data } \\
\text { Input }\end{array}$ & Skenario & Hasil & Keterangan \\
\hline $\begin{array}{c}\text { Penambahan } \\
\text { Data }\end{array}$ & Benar & $\begin{array}{c}\text { Form diisi dengan lengkap dan } \\
\text { sesuai lalu tekan tombol simpan }\end{array}$ & Data Tersimpan & Sesuai \\
Formulir & & & & \\
Hasil & & & & \\
Musyawarah & & Form diisi dengan tidak lengkap & $\begin{array}{c}\text { Menampilkan message } \\
\text { kesalahan yang harus } \\
\text { diperbaiki }\end{array}$ & Sesuai \\
\hline $\begin{array}{c}\text { Penambahan } \\
\text { Data }\end{array}$ & Salah & dan ada yang tidak sesuai & \\
Formulir & & & & \\
Hasil & & & & \\
Musyawarah & & & & \\
\hline
\end{tabular}

\section{KESIMPULAN}

Dari pembahasan yang telah diuraikan sebelumnya, dapat diambil beberapa kesimpulan yang berkaitan dengan Pengadministrasian Penyaluran Raskin yaitu sebagai berikut :

1. Pemanfaatan framework web seperti bootstrap dalam Sistem Informasi Pengelolaan Raskin yang dapat membantu Pelaksana Distribusi Raskin Desa Bintet Belinyu dalam mengelola penyaluran raskin agar proses pendataan calon penerima raskin tidak terlalu lama, tidak adanya nama penerima ganda, kesulitan dalam pencetakan kartu raskin serta pengiriman laporan penyaluran raskin kepada tim koordinasi kecamatan tepat waktu.

2. Dilakukan pengujian sistem pengadministrasian penyaluran Raskin menggunakan blackbox testing. Pengujian dilakukan dengan cara menjalankan aplikasi yang sudah ada.

3. Pengarsipan data penerima raskin tidak lagi membutuhkan banyak kertas dan tempat penyimpanan karena sudah tersimpan didalam sebuah Database Management Systems (DBMS).

\section{SARAN}

Saran yang ingin penulis sampaikan dalam penelitian penyaluran raskin, yaitu sebagai berikut : 
1. Dibutuhkan pelatihan kepada staff kelurahan dalam pengoperasian sistem informasi yang sudah dibuat agar terhindar human error sehingga implementasi sistem informasi berjalan baik, lancar dan dapat mengatasi masalah yang ada.

2. Staff kelurahan dan tim koordinasi raskin harus sering berkoordinasi apabila terdapat perubahan data

3. Tidak adanya grafik pada sistem informasi ini, untuk pengembangan penelitian selanjutnya dapat dibuat grafik yang komunikatif dan dinamis.

\section{UCAPAN TERIMA KASIH}

Penulis mengucapkan terima kasih kepada Yayasan Atma Luhur yang telah membiaya penelitian ini dan juga untuk sdri. Novalia yang melakukan penelitian bersama dan support pada penelitian ini.

\section{DAFTAR PUSTAKA}

[1] Komalasari, Tia Dwitiani, 2018, Jumlah Penduduk Miskin Indonesia Berkurang 1,19juta Orang, Pikiran Rakyat, Jakarta. https://www.pikiranrakyat.com/nasional/2018/01/02/jumlah-penduduk-miskin-indonesia-berkurang-119-jutaorang-417086

[2] Alimoeso, Surtarto, 2012, Pedoman Umum Penyaluran Beras Untuk Rumah Tangga Miskin, E Purwanto, Yogyakarta.

[3] Titis Aji Wicaksono, Siti Aminah, 2018, Sistem Informasi Pengelolaan Raskin pada Pelaksana Distribusi Raskin Desa Jatingarang, Journal Surya Informatika, vol 5, No. 1 November 2018 hal 34-43.

[4] Kamarudin Tone, 2016, Rancang Bangun Sistem Informasi Distribusi Bantuan Sosial Beras Miskin (Studi Kasus Kecamatan Binamu Kabupaten Jeneponto, Jurnal Instek, vol 1, No. 1 Oktober 2016.

[5] Suryati, Bambang Eka Purnama, 2010, Pembangunan Sistem Informasi Pendataan Rakyat Miskin Untuk Program Beras Miskin (Raskin) Pada Desa Mantren Kecamatan Kebonagung Kabupaten Pacitan, Journal Speed - Sentra Penelitian Engineering dan Edukasi, vol 2, No. 4 hal 32-41.

[6] Hamidah, Okkita Rizan.2016. Sistem Informasi Penjadwalan Dosen Ajar Studi Kasus: STMIK Atma Luhur. Jurnal Nasional Teknologi dan Sistem Informasi (Teknosi) Vol.2, No.1, Hal 65-74.

[7] Kadir, Abdul. 2003. Konsep dan Tuntunan Praktis BASIS DATA. Yogyakarta : ANDI.

[8] Sunarfrihantono, Bimo. 2002. PHP dan MySQL untuk Web. Yogyakarta: ANDI.

[9] Sutabri, Tata. (2012). Analisis Sistem Informasi. Yogyakarta : Andi.

[10] Sutabri, Tata. (2012). Konsep Sistem Informasi. Yogyakarta : Andi.

[11] Delpiah wahyuningsih, Hamidah Hamidah (2017). Sistem Informasi Eksekutif STMIK Atma Luhur Dengan Penerapan Customer Relationship Management Berbasis Website. Sisfonetika, 7(1). 